\title{
Toward a Global Scale Coastal Ocean Observing System
}

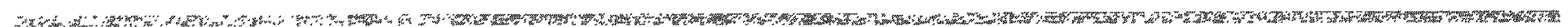

Thomas C. Malone

University of Maryland Center for Environmental Science - Cambridge, Maryland USA

Muriel Cole

National Oceanic and Atmospheric Administration - Washington, DC USA

\section{"Early detection of unacceptable changes in the environment could be the best insurance policy against environmental and economic train wrecks."}

Bruce Babbitt, Secretary, U.S. Department of the Interior

\section{What is the Global Ocean Observing System?}

The concept of the Global Ocean Observing System (GOOS) is that of an integrated global network that systematically acquires and disseminates data and data products in response to the information needs of government, industry, science and the public to address marine-related issues and problems in a timely fashion. The goals of GOOS are to improve (1) weather forecasts and climate predictions; (2) now-casting and forecasting for safe marine operations, the mitigation of natural hazards, and national security; and (3) detection and prediction of the effects of human activities and climate change on marine ecosystems and the living resources they support. The achievement of these goals will require the development of a comprehensive system of observations and analysis that not only builds on and supplements existing programs as appropriate, but also enables

- the shared use of infrastructure from measurement systems and platforms to communication networks and data management systems;

- problem-driven, rapid access to data from disparate sources; the incorporation of in situ and remote sensing, real-time data telemetry, data assimilation techniques, and modeling for more timely data analysis and synthesis;

- and a constructive and timely synergy between the detection of patterns of variability and hypothesisdriven research.
The "vision" is a public capable of making informed decisions based on knowledge of the causes and consequences of change in marine environments. Individuals and institutions with needs associated with the oceans should be confident that they have access to the data and information required to address issues that are relevant to them.

GOOS is a component of an Integrated Global Observing Strategy (IGOS) that includes the Global Climate Observing System (GCOS) and the Global Terrestrial Observing System (GTOS). It is sponsored by the Intergovernmental Oceanographic Commission (IOC), the United Nations Environmental Program (UNEP), the World Meteorological Organization (WMO), and the International Council of Scientific Unions (ICSU). International agreements that enable and call for the establishment of a GOOS include (1) the 1982 UN Convention on the Law of the Sea and (2) three conventions signed at the 1992 UN Conference on Environment and Development (UNCED) in Rio de Janeiro: the Framework Convention on Climate Change, Convention on Biodiversity and Program of Action for Sustainable Development, Agenda 21. The Law of the Sea Convention provides the legal basis for implementing GOOS by defining jurisdictions in the form of territorial seas and the EEZ. Agenda 21 calls for the establishment of a global ocean 
observing system that will enable effective and sustainable management and utilization of the marine environment and its natural resources.

In this regard, the importance of GOOS to education and research cannot be overstated. Most of our understanding of marine ecosystems is based on shipboard measurements that are limited to a sequence of measurements made at single locations in time and space and to data management and analytical capabilities that are inefficient and time consuming. Improved sensor technologies and high speed computers are providing the tools to overcome these limitations. Shipboard measurements that require the collection of water samples for subsequent analysis are gradually being augmented by continuous measurements from in situ sensors mounted on a diversity of platforms (towed instrument packages, fixed moorings, drifters, AUVs, ROVs) and from remote sensors on aircraft and satellites that transmit data in real-time. As data assimilation techniques improve, applications of environmental data for the purposes of education and research will expand rapidly to include such capabilities as near real-time, 3dimensional, time-dependent visualizations of environmental change in marine systems (circulation patterns, the evolution of hypoxic and harmful algal events, habitat loss, etc.), rapid detection of trends, and the development of improved models for prediction and experimentation. These emerging capabilities are not only needed to advance environmental science and improve science education in the classroom, they are of fundamental importance to the design and implementation of the ocean observing system.

\section{GOOS: From Concept to Reality}

The effort to make the transition from concept to reality is being lead by a GOOS Steering Committee (the GSC chaired by Worth Nowlin) which is responsible for the design and implementation of GOOS. An intergovernmental committee (I-GOOS) assists in gaining government approval of and support for implementation. Four advisory panels report to the GSC: an Ocean Observing Panel for Climate (OOPC, chaired by Neville Smith), Health Of The Oceans (HOTO, chaired by Tony Knap), Coastal (C-GOOS, chaired by Tom Malone), and Living Marine Resources (LMR, chaired by Warren Wooster). Recently, a Capacity Building panel has been formed to draft plans to enable developing nations to participate in and benefit from GOOS. It is likely that implementation will proceed along two parallel tracks: one for coastal monitoring and prediction and one for open ocean monitoring and prediction. Since most issues involving the health of the oceans and living marine resources are related to environmental variability in the coastal zone, the HOTO, C-GOOS and LMR modules will soon be merged into a single panel to develop recommendations for the formulation of a common set of design and implementation plans for the coastal ocean.
If the goals of GOOS are to be achieved, observations must be sustained and integrated (Figure 1). Observations must be sustained in perpetuity to capture episodic events and long-term trends, enhance scientific analysis, and support model predictions. ${ }^{1}$ The observing system must also be integrated in terms of the interdisciplinary, multidimensional, and multi-scale nature of environmental change. To date, no single program is both integrated and sustained. For example, numerical weather predictions and sea level measurements are sustained but not integrated. IGBP programs such as LOICZ, JGOFS, GLOBEC, and GEOHAB (see glossary for definitions) are integrated in the sense that they are interdisciplinary in scope, but they are not sustained.

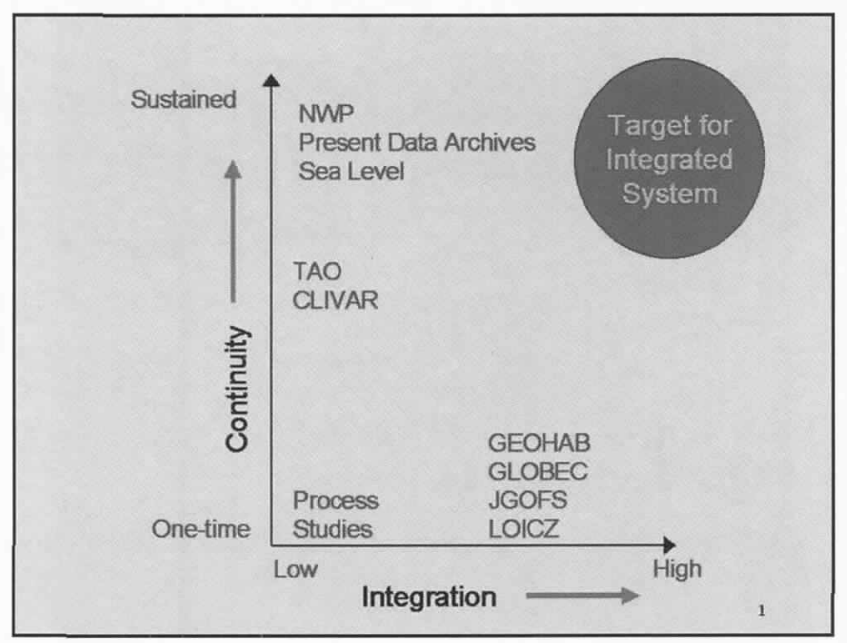

Figure 1. Most environmental programs are characterized either by their continuity (they are sustained) or by the extent to which they are integrated. Very few programs are both sustained and integrated. The Global Ocean Observing System is conceived as both sustained and integrated.

In addition to being sustained and integrated, the observing system must be responsive to user needs. Measurements must be routine with known precision and accuracy; data must be assimilated, analyzed and transformed into products in a timely fashion; and the entire process from measurements to products must be cost-effective. GOOS is conceived as an "end-to-end, user-driven" system, the operational objective of which is to develop a locally relevant, global scale observing system for multiple uses that is sustained, integrated, and operational. To this end, the GOOS Panels are working together to

- specify the measurement programs and information required on a continuing basis to meet user group needs on local to global scales;

\footnotetext{
"Note: The term "prediction" is used here in its broadest sense to include forecasting or predicting future events as well as estimating (interpolating, extrapolating) a quantity which is not observed directly.
} 
- design and promote the implementation of an internationally coordinated strategy for the timely acquisition, dissemination, analysis and archival of data;

- incorporate existing programs as appropriate to minimize redundancy and optimize shared use capabilities;

- tenable all nations to participate and benefit from GOOS; and coordinate with GCOS and GTOS to insure the full integration of environmental data and information.

The development of regional and national GOOS efforts is of critical importance to the implementation of end-to-end, user driven observing systems, especially in coastal waters. Regional programs have been launched in Europe (EuroGOOS), the Mediterranean (MedGOOS), Africa (GOOS Africa) and North East Asia (NEAR-GOOS). National GOOS programs are also being developed by several countries including Brazil, China, Japan, South Korea, and the United States.

\section{Coastal-GOOS}

GOOS includes the ocean component of GCOS and the coastal marine component of GTOS and its devel- opment reflects these relationships. The oceanic subsystem is primarily concerned with the role of the oceans in global climate change. In contrast, the coastal subsystem must take into account the reality that the combined effects of global climate change and human alterations of the environment are especially pronounced in the coastal zone where population density is increasing most rapidly. It is here that the conflicts and challenges of promoting economic development, sustaining living resources, protecting and restoring ecosystem health, mitigating natural disasters, and protecting public health and safety will become most pronounced over the foreseeable future. Changes in coastal ecosystems (Table 1) are globally ubiquitous; they indi-
canges in the capacity of coastal ecosyscate profound changes in the capacity of coastal ecosys-
tems to support living resources; and they are making the coastal zone more susceptible to "natural" hazards (e.g. tropical storms, flooding, droughts, harmful algal blooms), more costly to live in, and of less value to the national economy.

Although the list of indicators of environmental change in coastal waters is long, they are related in terms of ecosystem dynamics suggesting that there is a common set of core properties that, if measured with

Table 1. Prominent natural perturbations and anthropogenic stresses and associated indicators of change in coastal aquatic ecosystems.

\section{PERTURBATION}

* Storms and annual weather cycles (e.g. wind, precipitation, storm surge, freshwater runoff)

$\star$ Climate change

$\star$ Physical restructuring of the environment

$\star$ Nutrient mobilization and enrichment

$\star$ Chemical contamination

$\star$ Exploitation of natural resources

$\star$ Introductions of nonindigenous (exotic) species

\section{INDICATORS OF CHANGE}

$\star$ Decline and loss of living resources

$\star$ Habitat loss, oxygen depletion and erosion

$\star$ Accumulations of algal biomass and harmful algal events

Mass mortalities of fish, birds and mammals

Diseases and accumulation of chemical contaminants in marine organisms

Loss of biodiversity and the growth of nonindigensous species

$\star$ Temperature increase, sea level rise and salt intrusions

Increased susceptibility to natural hazards Increased public health risk 
sufficient resolution in time and space, can significantly contribute to the information needs of a diversity of user groups. Achievement of a predictive understanding of environmental change requires both the comparative analysis of coastal ecosystems on a global scale and observations of local ecosystems that are made and evaluated in the context of larger scale changes in ocean circulation, climate, and land-use practices. To these ends, the design and implementation of the coastal subsystem of GOOS must address four major impediments to the development of a predictive understanding of environmental variability and change:

- the scarcity of observations of sufficient duration, spatial extent, and resolution;

- the lack of synoptic (simultaneous in time and space) measurements of key physical, geological, chemical and biological attributes of coastal ecosystems;

- the paucity of real-time data telemetry, assimilation and analysis; and

- the absence of an integrated system of data management that both captures the diversity of data types and enables timely access to disparate data sets.

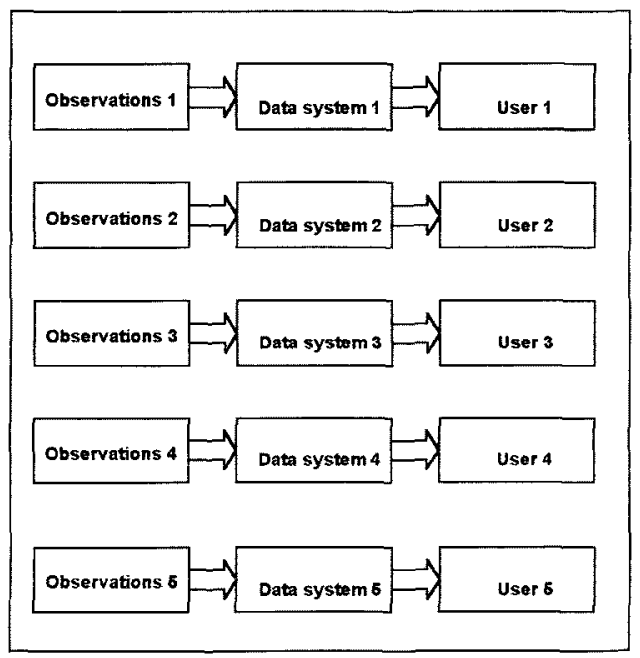

Figure 2. Historically, programs have been developed independently by different groups to address specific issues and mission based goals.

In the past, programs of environmental research and monitoring were developed independently, case-bycase by different groups to address specific issues and mission based goals (Figure 2). Consequently, there are a plethora of programs that employ different platforms and methods, make measurements on different time and space scales, and use different data management systems designed for the purposes of a particular agency, institution or program. As the multi-disciplinary nature of most environmental issues became clear, efforts to collate and integrate data from a variety of disparate sources have increased (Figure 3). Under present conditions, this is an expensive and time consuming process that inhibits the timely analysis of data and severely limits the development of a predictive understanding of change in coastal ecosystems. The objective is an integrated system that allows users to exploit multiple data sets from a variety of disparate sources through "one stop shopping" (Figure 4).

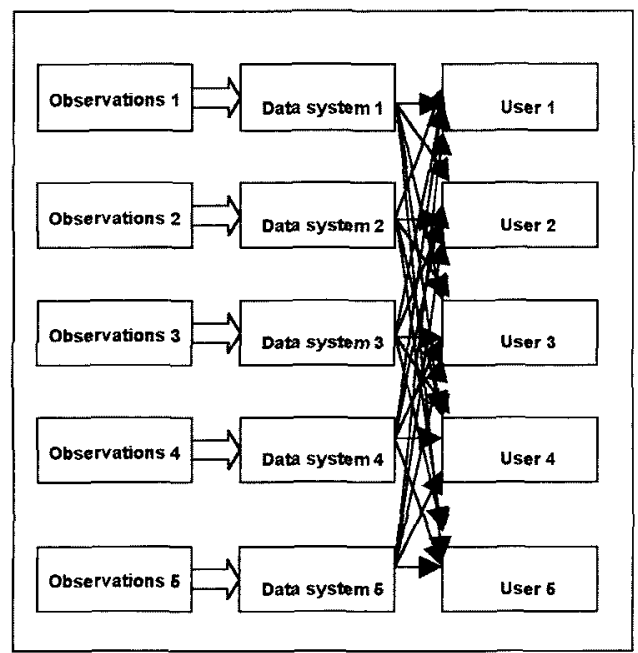

Figure 3. As the interdisciplinary and multidimensional nature of enviromitental issues became clear, efforts to collate and synthesize data from multiple sources have increased. Under present conditions, this is an expensive and time consuming process that inlibits the timtely analysis of data and severely limits the development of predictive capabilities.

\section{The U.S. Response}

Within the U.S., recent reports of the National Research Council call for the development of integrated ocean observing systems ( http://www.nap.edu), and both the executive (the Administration) and legislative (the Congress) branches of government have become increasingly cognizant of the need for GOOS. At the National Ocean Conference in June, 1998, the Administration emphasized its commitment to "...launch new partnerships with states, local communities, and the private sector to reduce pollution [and inform the public]..., and to develop a new and sophisticated ocean monitoring system to give us a better understanding..." Also in 1998, Congress held hearings on the need for ocean observations and commissioned a plan by the National Ocean Research Leadership Council (composed of high-level officials from 12 federal agencies) to achieve a truly integrated ocean observing system. With funding support from NOAA, U.S. GOOS support offices were established at Texas A\&M University and the University of Maryland Center for Environmental Science to initiate plans for the oceanic and coastal components of GOOS. A U.S. GOOS 
Steering Committee (composed of representatives from academia, industry, government, and environmental organizations) was formed to provide guidance for the design and implementation of U.S. GOOS. Subsequently, Congress called for the formulation of plans for an "integrated ocean observing system." This led to the drafting of a plan, "Toward a U.S. Plan for an Integrated, Sustained Ocean Observing System" (IOOS), which was transmitted to Congress in April, 1999 http:/ / core.cast.msstate.edu/NOPPobsplan.html). The report was submitted as an initial draft of a "living document", and work has continued under the auspices of the Ocean Research Advisory Panel (ORAP, chaired by John Knauss) to draft the next phase of the plan.

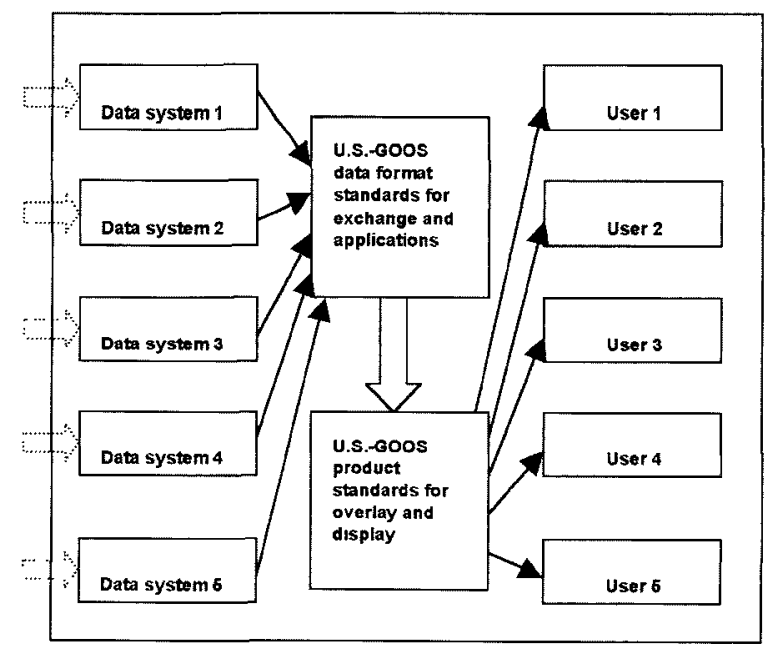

Figure 4. The objective is an integrated system that allows users to exploit multiple data sets from a variety of disparate sources through "one stop shopping." The linkages between measurements and data integration are internal to the observing system and transparent to users.

The new plan, which is expected to be completed in early 2000, will address issues of governance, integration, and funding for both the oceanic and coastal subsystems. In addition to building on the initial plan, the effort will incorporate community input from a variety of sources including the following:

- recommendations of the Consortium for Oceanographic Research and Education, "A National Initiative to Observe the Oceans: A CORE Perspective"

(http://core.cast.msstate.edu/observe.html);

- the NOAA-EPA initiative to develop a national coastal research and monitoring strategy (called for by the Clean Water Action Plan); and

- recommendations from a recent U.S. C-GOOS workshop report, "An Ocean Observing System for U.S. Coastal Waters, First Steps"

(http:/ / www.hpl.umces.edu/projects/wrkrpt.pdf).

The U.S. C-GOOS workshop brought together representatives from government (state and federal agencies) and academia who have direct, hands on experience with and responsibility for in situ sensing (platforms or sensors), remote sensing, real time telemetry, data assimilation techniques, systems modeling, and the stewardship of coastal environments and living resources. The purpose of the workshop was to evaluate requirements for and the ingredients of an integrated coastal ocean observing system. Participants were asked to address three related issues: (1) detecting and predicting change in coastal ecosystems; (2) monitoring capabilities and information needs; and (3) the design and implementation of the coastal component of the IOOS. Workshop goals were to

- contribute to the next iteration of "Toward a U.S. Plan For an Integrated, Sustained Ocean Observing System" with particular reference to coastal issues;

- acquaint state managers with the potential of in situ and remote sensing as sources of information upon which to base management policies, plans, and decisions; and

- acquaint scientist with the needs and perspectives of coastal managers responsible for the stewardship of coastal environments and the living resources they support.

Five papers were commissioned in advance to set the stage and stimulate discussion. This publication is the product of these efforts. 